\begin{tabular}{|c|l|}
\hline Title & Clinical features of abruptio placentae as a prominent cause of cerebral palsy \\
\hline Author(s) & Y amada, Takahiro; Y amada, Takashi; Morikawa, Mamoru; Minakami, Hisanori \\
\hline Citation & $\begin{array}{l}\text { Early Human Development, 88(11), 861-864 } \\
\text { https://doi.org/10.1016/.earlhumdev.2012.06.008 }\end{array}$ \\
\hline Issue Date & 2012-11 \\
\hline Doc URL & http://hdl.handle.net/2115/50555 \\
\hline Type & article (author version) \\
\hline File Information & EHD88-11_861-864.pdf \\
\hline
\end{tabular}

Instructions for use 
[ORIGINAL ARTICLE] for Early Hum Dev

\section{Clinical features of abruptio placentae as a prominent cause of cerebral palsy}

Takahiro Yamada, Takashi Yamada, Mamoru Morikawa, Hisanori Minakami

Affiliation of all authors: Department of Obstetrics,

Hokkaido University Graduate School of Medicine, Sapporo, Japan

Correspondence to: Takahiro Yamada, M.D. Ph.D.

Department of Obstetrics, Hokkaido University Graduate School of Medicine, Kita-ku N15 W7, Sapporo 060-8638, Japan

Phone: +81-11-706-5941: Fax: +81-11-706-7711

E-mail: taka0197@med.hokudai.ac.jp

Running foot: Abruptio placentae-induced cerebral palsy 


\begin{abstract}
Background: Although abruptio placentae causes hypoxia in the infant and thus leading to cerebral palsy (CP), its incidence and clinical features at a nation wide level have not been demonstrated.
\end{abstract}

Aims: To determine the proportion of abruptio placentae among antenatal and intrapartum causative factors leading to cerebral palsy $(\mathrm{CP})$ and clinical features of such abruptio placentae.

Study design: A review was conducted in 107 infants with $\mathrm{CP}$ in whom CP was determined to be due to antenatal and or intrapartum hypoxic conditions by the Japan Council for Quality Health Care until April 2012.

Results: Abruptio placenta was responsible for 28 (26\%) of the $107 \mathrm{CP}$ infants, and was the single leading causative factor of CP. Of these 28 women, $22(79 \%)$ exhibited non-reassuring fetal status on admission to obstetric facilities at $36.2 \pm 2.6$ weeks of gestation and had neonates with umbilical cord arterial blood $\mathrm{pH}$ (base excess) of 6.728 $\pm 0.164(-25 \pm 5.4 \mathrm{mmol} / \mathrm{L})$. In these 22 women, strong abdominal pain and/or profuse vaginal bleeding occurred $159 \pm 99$ min prior to admission to an obstetric facility, and the interval until delivery after admission was $47 \pm 31 \mathrm{~min}$. Hypertension or isolated proteinuria preceded clinical events in one $(4.5 \%)$ and five $(23 \%)$ of these 22 women, respectively.

Conclusions: Abruptio placentae was responsible for $\mathrm{CP}$ in one quarter of all cases determined to be due to antenatal and/or intrapartum hypoxic conditions in Japan. New strategies to shorten the interval until admission to an obstetric facility after onset of symptoms are urgently needed.

Key words: abdominal pain, cerebral palsy, abruption placentae, vaginal bleeding, 
Yamada et al. Abruptio placentae-induced cerebral palsy

proteinuria 


\section{Introduction}

Although some pregnant women develop abruptio placentae during their stay in an obstetric facility $[1,2]$, others show non-reassuring fetal status (NRFS) caused by abruptio placentae at presentation [3]. As abruptio placentae is one of the leading causes of cerebral palsy (CP) derived from antepartum and/or intrapartum hypoxic conditions [4-8], prompt delivery may be important to avoid neurological handicap in the infants $[3,9,10]$. Women who develop abruptio placentae at obstetric facilities may have a shorter interval until delivery after the onset of symptoms and may be less likely to have infants with CP. Therefore, there may be large numbers of women who develop abruptio placentae outside obstetric facilities and have infants with CP. However, there is little information in the literature regarding this issue.

The Japanese government established a new medical insurance system, the Japan Obstetric Compensation System for Cerebral Palsy, to compensate for cerebral palsy (CP) derived in principle from intrapartum hypoxia and to improve perinatal care, and asked the Japan Council for Quality Health Care (JCQHC) to organize this system. This system was launched on 1 January 2009, and provides rapid monetary compensation for CP [11] certified as $1^{\text {st }}$ or $2^{\text {nd }}$ degree severity according to the criteria of the Japanese Social Welfare System [12] in infants with birth weight $>2000 \mathrm{~g}$ and/or pregnancy length $>33$ weeks. Infants who do not meet the above criteria but are born at $>28$ weeks are also eligible for compensation after case-by-case review [11]. This system, however, does not cover infants with disability apparently due to congenital anomalies in metabolism, chromosomal aberrations, brain malformations, transplacental infection, or postnatal factors [11]. More than 99\% of pregnant women and more than $99 \%$ of obstetric facilities in Japan participate in this system. Once a patient with $\mathrm{CP}$ applies for 
compensation, the obstetric facility that managed the applicant must disclose corresponding medical charts and relevant information at the request of the JCQHC. The decision for compensation in each case is made by the JCQHC after preliminary investigations. Then, a professional committee belonging to the JCQHC, consisting of physicians, midwives, lawyers, and citizens, investigates the causative factors in $\mathrm{CP}$ carefully in each case and publishes a brief summary of each case together with the cause of $\mathrm{CP}$ in a form with privacy protection on their website [13]. Researchers can gain access to a more detailed report made by the committee after being approved by the JCQHC in this system.

Accordingly, the present study was performed to determine the frequency of abruptio placentae among the antepartum and/or intrapartum causative factors leading to neonatal encephalopathy, and finally to cerebral palsy (CP), how many patients developed antepartum abruptio placentae at and outside obstetric facilities, and clinical features of such antepartum abruptio placentae.

\section{Materials and Methods}

This study was approved by the Ethics Committee of Hokkaido University Hospital. We were provided access by the JCQHC to all 111 detailed reports made up until April 2012, in which clinical courses of 111 infants born to 111 women and results of the investigations regarding the causes of $\mathrm{CP}$ were recorded. In these reports, personal information regarding the date of birth, including year and month, place of birth, and maternal age, were masked for privacy protection. However, all 111 infants were born in or after January 2009, because this compensation system was instigated on 
1 January 2009. These 111 reports were retrospectively reviewed focusing on clinical backgrounds and causes of CP. Women who developed hypertension (systolic blood pressure $\geq 140 \mathrm{mmHg}$ or diastolic blood pressure $\geq 90 \mathrm{mmHg}$ ) alone, proteinuria $(\geq 1+$ on dipstick test at the last two successive antenatal visits, or $\geq 2+$ on dipstick test at the last antenatal visit) alone, or both hypertension and proteinuria at and after 20 weeks of gestation were diagnosed as having gestational hypertension, isolated proteinuria, or preeclampsia, respectively.

The JCQHC announced in May 2012 that a total of 171 infants born in 2009 were compensated for their CP until the end of March 2012.

\section{Results}

In 4 of the 111 patients, $\mathrm{CP}$ was determined not to have been caused by antepartum and/or intrapartum hypoxic conditions: vertical transmission of group B streptococcus, neonatal apnea, neonatal pneumonitis, and congenital metabolic disorder were determined to be responsible for one case each. Antepartum and/or intrapartum factors leading to neonatal encephalopathy were recognized in the remaining 107 infants (Table 1). Abruptio placentae explained 28 (26\%) of the 107 cases of $\mathrm{CP}$ derived from antepartum and/or intrapartum hypoxic conditions and was the single leading causative factor of CP. Among the 28 patients with abruptio placentae-induced CP, as many as 22 (79\%) exhibited NRFS on admission to the obstetric facilities (Table 1).

Of the 22 women who had both abruptio placentae and NRFS at admission, only 4 (18\%) were primiparous (Table 2). Gestational hypertension was recognized at the last antenatal visit in one patient (Case 3). Isolated proteinuria was seen in 5 patients at the last antenatal visit (Cases 15, 17, 18, 20, and 22), in whom preeclampsia was diagnosed 
several hours prior to the onset of symptoms in Case 15. Gestational hypertension was seen in an additional 2 patients on admission (Cases 5 and 9).

These 22 patients gave birth to infants with birth weight of $2473 \pm 454 \mathrm{~g}$ at $36.2 \pm$ 2.6 weeks of gestation (Table 2); $9(41 \%)$ at preterm, $14(64 \%)$ with a low birth weight of less than $2500 \mathrm{~g}$; and $17(77 \%)$ with a 5-min Apgar score of less than 5. All except one infant (Case 18) for whom umbilical arterial blood gas data were available showed a $\mathrm{pH}$ of less than 7.0 with a marked base deficit and extremely low mean $\mathrm{pH}$ (base excess $)$ of $6.728 \pm 0.164(-25.0 \pm 5.4 \mathrm{mmol} / \mathrm{L})$. The 22 patients experienced exclusively strong abdominal pain and/or profuse vaginal bleeding, and therefore visited an obstetric facility $159 \pm 99$ min after the onset of symptoms: only $4(18 \%)$ visited within 90 min after the onset of symptoms. After arrival at the obstetric facility, it took $47 \pm 31$ min for the delivery of infants, and was more than $30 \mathrm{~min}$ in 13 patients (59\%).

\section{Discussion}

The present study demonstrated that abruptio placentae is the single leading causative factor of $\mathrm{CP}$ derived from antenatal and/or intrapartum hypoxic conditions in Japan, accounting for approximately one quarter (28/107) of CP cases. Twenty-two of the 28 women (79\%) with abruptio placentae exhibited NRFS at the time of admission to the obstetric facility.

As no data were available for comparison, it was not clear whether the figure of $79 \%$ (22/28) for the proportion of women who presented with NRFS among those with abruptio placentae was high. However, as these 22 events accounted for $21 \%$ of all 107 events leading to $\mathrm{CP}$ in infants, it may be helpful to focus on these 22 patients for the 
Yamada et al. Abruptio placentae-induced cerebral palsy

development of preventive measures and to reduce the number of such cases.

The speed of response may influence the outcome of infants born to women with complications such as abruptio placentae, cord prolapse, and uterine rupture $[3,9,10]$ : "examples of conditions cited by the American Academy of Pediatrics and ACOG that may require delivery within 30 minutes include hemorrhage from placenta previa, placental abruption, umbilical cord prolapse, and uterine rupture" [10]; among 126 emergent (crash) cesarean deliveries, 10, 8, and 6 were for umbilical cord prolapse, abruptio placentae, and suspected uterine rupture, respectively, in a hospital in USA. Such patients with emergent (crash) cesarean deliveries indeed showed increased risks of low 5-min Apgar score and infant intubation [9], likely attesting to the need for expedited delivery. Among 33 infants born to women presenting with abruptio placentae and fetal bradycardia at admission, 22 infants with no developmental delay had significantly shorter "decision to time of delivery" compared with 11 infants who died or survived with $\mathrm{CP}$ (median: 14.5 vs. $24.0 \mathrm{~min}, P=0.02$ ) [3]. Thus, most researchers consider that expedited delivery may improve outcome of patients with abruptio placentae based on earlier findings [14 - 16]: duration of fetal heart rate deceleration during the end stage of labor are associated with acidotic $\mathrm{pH}$ of the umbilical vein blood [14]; fetal acidosis is common if the bradycardia lasts for $10 \mathrm{~min}$ or more, particularly if the heart rate is $<80 \mathrm{bpm}$ with decreased variability [15]; and the incidence of $\mathrm{CP}$ is approximately $1.0 \%$ in full-term surviving neonates with an Apgar score of $0-3$ at $5 \mathrm{~min}$, while the values are $9 \%$ and $57 \%$ if this score is sustained for 15 and $20 \mathrm{~min}$, respectively [16]. 
The 22 patients were admitted to an obstetric facility $159 \pm 99$ min after the onset of symptoms and a further $47 \pm 31 \mathrm{~min}$ were required for the delivery of infants after arrival at the obstetric facility. This resulted in an extremely low umbilical arterial blood $\mathrm{pH}$ of $6.728 \pm 0.164$ with base excess $(-25 \pm 5.4 \mathrm{mmol} / \mathrm{L})$ in these cases. As a large number of obstetric facilities (3333 facilities) participated in the Japan Obstetric Compensation System for Cerebral Palsy (cited 7 June 2012; available from http://www.sanka-hp.jcqhc.or.jp/search/kanyujokyo.php), most of these 22 patients may have resided within $30 \mathrm{~km}$ from the obstetric facility booked for parturition, suggesting that they were able to be admitted to the obstetric facility within 60 min after symptom onset if they so wished. Although no differences were reported in time interval after the onset of symptoms until admission to hospitals between women with fetal bradycardia caused by abruptio placentae at admission having children with no developmental delay and $\mathrm{CP}$ (median: 60 vs. $105 \mathrm{~min}$, respectively, $P=0.59$ ) [3], an earlier visit to the obstetric facility would have enhanced the possibility of having infants without $\mathrm{CP}$ in these 22 patients in this study.

Hypertension preceded events in only one of the 22 women in this study. Therefore, focusing on patients with hypertensive disorders may not contribute to the reduction of such cases presenting with NRFS caused by abruption placentae. Rather, attention should be paid to women with isolated proteinuria; this study demonstrated that isolated proteinuria preceded events in 5 of the 22 patients $(23 \%)$ suggesting that isolated proteinuria is a risk factor for not only the development of preeclampsia $[17,18]$ and eclampsia [19, 20], but also for the development of abruptio placentae. Abruptio placentae occurs in $0.4 \%-1.0 \%$ of women in many countries [22-27]. Abruptio 
placentae accounts for $4.0 \%-6.0 \%$ of preterm delivery $[22-24,26]$, and that occurring at preterm accounts for $40 \%-50 \%$ of all cases of abruptio placentae [22, 23, 26]. Fortunately, most women complain of abdominal pain and/or vaginal bleeding, leading to suspicion of abruptio placentae as in the present study, although predictive characteristics of such clinical signs for the development of abruptio placentae are unknown at present. Pregnant Japanese women were unfamiliar with abruptio placentae because most women were not informed about this life-threatening complication. Thus, it is necessary to determine the best way to inform pregnant women about this complication before 30 weeks of gestation.

The strength of our study was that the Japan Obstetric Compensation System for Cerebral Palsy established in 2009 [11] is expected to collect information on the clinical courses of all patients with both CP and a birth weight $>2000 \mathrm{~g}$ in and after January 2009 in Japan and in whom intrapartum factors are possible causes of CP, because compensation of approximately US\$370000 would be provided in cases in which intrapartum factors were judged to be causative of CP. In addition, there are no restrictions of the right to sue for malpractice even after compensation by this system. Therefore, the number of patients with $\mathrm{CP}$ associated with abruptio placentae presented here likely reflected the true number of such cases with certified $1^{\text {st }}$ or $2^{\text {nd }}$ degree severity according to the criteria of the Japanese Social Welfare System [12] that occurred in Japan during a certain period that we were unable to specify because the date of birth for each case was masked. This limitation also hampered the estimation of absolute risk of $\mathrm{CP}$ associated with abruptio placentae in Japan, which has an annual birth rate of approximately 1050000 infants with birth weight $>2000 \mathrm{~g}$ [tabulation 
information released annually by the Japanese Ministry of Health, Labor, and Welfare]. In May 2012, the JCQHC announced that a total of 171 infants born in 2009 were compensated for CP until the end of March 2012. Thus, it was expected that these 107 study subjects were born during a period of an approximately 7.5 months in 2009 and were diagnosed with $\mathrm{CP}$ before the end of 2011, suggesting that the prevalence of $\mathrm{CP}$ derived from antenatal and/or intrapartum hypoxic conditions was 0.16 per 1000 births $(107 / 656000 ; 1050000 \times 7.5 / 12)$. The prevalence of whole CP was reported to be $1.5-$ 2.5 per 1000 live births [28]. If we assume that antenatal and intrapartum hypoxic conditions account for approximately $10 \%$ - $15 \%$ of all cases of $\mathrm{CP}$ according to previous reports [29, 30], our estimated figure, 0.16 per 1000 births, was somewhat lower, but would be reasonable, because some infants born in 2009 will be diagnosed with $\mathrm{CP}$ in the near future.

In conclusion, the new Japan Obstetric Compensation System for Cerebral Palsy allowed the collection of information regarding the clinical courses of 107 infants with $\mathrm{CP}$ derived from antenatal and/or intrapartum hypoxic conditions. Abruptio placentae presenting with NRFS at admission accounted for approximately one fifth of all cases of CP (22/107) derived from antenatal and/or intrapartum hypoxic conditions. These 22 women visited obstetric facilities approximately $160 \mathrm{~min}$ after the onset of abdominal pain and/or vaginal bleeding. Providing information on the nature of abruptio placentae to all pregnant women before 30 weeks of gestation should be considered to reduce the time interval after the onset of symptoms until admission to an obstetric facility.

\section{Conflict of Interest}


Yamada et al. Abruptio placentae-induced cerebral palsy

All authors declare that they have no financial relationships with biotechnology manufacturers, pharmaceutical companies, or other commercial entities with an interest in the subject matter or materials discussed in this manuscript. 


\section{References}

1. Fontenot MT, Lewis DF, Barton CB, Jones EM, Moore JA, Evans AT. Abruptio placentae associated with misoprostol use in women with preeclampsia. J Reprod Med 2005;50:653-8.

2. Martinez de Tejada B, Martillotti G, Lapaire O, Hoesli I, Irion O. The risk of placental abruption when using prostaglandins for cervical ripening in women with preeclampsia: comparing misoprostol versus dinoprostone. J Matern Fetal Neonatal Med 2010;23:988-93.

3. Kayani SI, Stephen A. Walkinshaw SA, Preston C. Pregnancy outcome in severe placental abruption. Br J Obstet Gynaecol 2003;110:679-83.

4. Stelmach T, Pisarev H, Talvik T. Ante- and perinatal factors for cerebral palsy: case-control study in Estonia. J Child Neurol 2005;20:654-61.

5. Thorngren-Jerneck K, Herbst A. Perinatal factors associated with cerebral palsy in children born in Sweden. Obstet Gynecol 2006;108:1499-1505

6. Himmelmann K, Hagberg G, Wiklund LM, Eek MN. Dyskinetic cerebral palsy: a population-based study of children born between 1991 and 1998. Dev Med Child Nerurol 2007;49:246-51.

7. Nelson KB. Causative factors in cerebral palsy. Clin Obstet Gynecol 2008;51:749-62.

8. Gilbert WM, Jacoby BN, Xing G, Danielsen B, Smith LH. Adverse obstetric events are associated with significant risk of cerebral palsy. Am J Obstet Gynecol 2010;203:328.e1-5.

9. Lagrew DC, Bush MC, Mckeown AM, Lagrew NG. Emergent (crash) cesarean delivery: indications and outcomes. Am J Obstet Gynecol 2006;194:1638-43. 
Yamada et al. Abruptio placentae-induced cerebral palsy

10. Bloom SL, Leveno KJ, Spong CY, Gilbert S, Hauth JC, Landon MB, et al.

Decision-to-incision times and maternal and infant outcome. Obstet Gynecol 2006;108:6-11.

11. The Japan Council for Quality Health Care. Guide to The Japan Obstetric Compensation system for Cerebral Palsy. [Cited 2 March 2012.] Available from http://www.sanka-hp.jcqhc.or.jp/pdf/bira_english_color201109.pdf

12. The Japanese Social Welfare System. Criteria for determining degree of disabilities. http://www.pref.aichi.jp/shogai/04shougaisha/shogai-kijun/0404nougensei.html (accessed 2 Mar 2012).

13. The Japan Council for Quality Health Care. Brief report on the cause of cerebral palsy. [Cited 2 March 2012.] Available from http://www.sanka-hp.jcqhc.or.jp/outline/report.html

14. Katz M, Shani N, Meizner I, Insler V. Is end-stage deceleration of the fetal heart ominous? BJOG 1982;89:186-9.

15. Ingemarsson I, Arulkumaran S, Ratnam SS. Single injection of terbutaline in term labor. Am J Obstet Gynecol 1985;153:859-65.

16. Brann AW Jr. Hypoxic ischemic encephalopathy (asphyxia). Pediatr Clin N Am $1986 ; 33: 451-64$.

17. Morikawa M, Yamada T, Yamada T, Cho K, Yamada H, Sakuragi N, Minakami H. Pregnancy outcome of women who developed proteinuria in the absence of hypertension after mid-gestation. J Perinat Med 2008;36:419-24.

18. Morikawa M, Yamada T, Minakami H. Outcome of pregnancy in patients with isolated proteinuria. Curr Opin Obstet Gynecol 2009;21:491-5. 
19. Douglas KA, Redman CWG: Eclampsia in the United Kingdom. BMJ 1994; 309: $1395-1400$.

20. Knight M on behalf of UKOSS: Eclampsia in the United Kingdom 2005. Br J Obstet Gynaecol 2007; 114: 1072-1078.

21. Matsuda Y, Hayashi K, Shiozaki A, Kawamichi Y, Satoh S, Saito S. Comparison of risk factors for placental abruption and placenta previa: case-cohort study. J Obstet Gynaecol Res 2011;37:538-46.

22. Sheiner E, Shoham-Vardi I, Hadar A, Hallak M, Hackmon R, Mazor M. Incidence, obstetric risk factors and pregnancy outcome of preterm placental abruption: a retrospective analysis. J Matern Fetal Neonatal Med 2002;11:34-9.

23. Sheiner E, Shoham-Vardi I, Hallak M, Hadar A, Gortzak-Uzan L, Katz M, Mazor M. Placental abruption in term pregnancies: clinical significance and obstetric risk factors. J Matern Fetal Neonatal Med 2003;13:45-9.

24. Ananth CV, Vintzileos AM. Maternal-fetal conditions necessitating a medical intervention resulting in preterm birth. Am J Obstet Gynecol 2006;195:1557-63. 25. Tikkanen M, Riihimäki O, Gissler M, Luukkaala T, Metsäranta M, Andersson S, Ritvanen A, Paavonen J, Nuutila M. Decreasing incidence of placental abruption in Finland during 1980-2005. Acta Obstet Gynecol Scand 2012 May 15. doi: 10.1111/j.1600-0412.2012.01457.x. [Epub ahead of print] 26. Ananth CV, Berkowitz GS, Savitz DA, Lapinski RH. Placental abruption and adverse perinatal outcomes. JAMA 1999; 282; 1646-51.

27. Pariente G, Wiznitzer A, Sergienko R, Mazor M, Holcberg G, Sheiner E. 
Yamada et al. Abruptio placentae-induced cerebral palsy

Placental abruption: critical analysis of risk factors and perinatal outcomes. J Matern Fetal Neonatal Med 2011 May;24(5):698-702. Epub 2010 Sep 9.

28. Kuban KCK, Leviton A. Cerebral palsy. N Engl J Med 1994;330:188-95.

29. Nelson KB, Ellenberg JH. Antecedents of cerebral palsy. N Engl J Med $1986 ; 315: 81-6$.

30. Graham EM, Ruis KA, Hartman AL, Northington FJ, Fox HE. A systematic review of the role of intrapartum hypoxia-ischemia in the causation of neonatal encephalopathy. Am J Obstet Gynecol 2008; 199: 587-95. 
Table 1. Causative factors in the 107 infants with cerebral palsy

$\begin{array}{lll}\text { Abruptio placentaeII } & 28(22) & {[26.2 \%]} \\ \text { Umbilical cord prolapse } & 7(1) & {[6.5 \%]} \\ \text { Uterine rupture } & 4(1) & {[3.7 \%]} \\ \text { Twin* } & 4(2) & {[3.7 \%]} \\ \text { Fetomaternal transfusion } & 2(2) & {[1.9 \%]} \\ \text { Breech vaginal delivery } & 1(0) & {[0.9 \%]} \\ \text { Shoulder dystocia } & 1(0) & {[0.9 \%]} \\ \text { Low-lying placenta } \dagger & 1(0) & {[0.9 \%]} \\ \text { Anesthetic accident } & 1(0) & {[0.9 \%]} \\ \text { Birth in a motor car } & 1 & {[0.9 \%]} \\ \text { Others } & 57(15) & {[53.3 \%]}\end{array}$

Of $111 \mathrm{CP}$ infants, 4 in whom CP was determined not to have been caused by antepartum and/or intrapartum hypoxic conditions were excluded. "Others" included factors not specified in this table. Numbers of infants exhibiting non-reassuring fetal status on electronic cardiotocogram at admission to obstetric facilities are indicated in parentheses. Percentages of 107 cases are indicated in square brackets. II, Including one breech vaginal delivery; *, One case was caused by twin-twin transfusion syndrome; $\uparrow$, Bleeding from the placenta was responsible for CP. 
Table 2. Twenty-two cases of abruptio placentae showing non-reassuring fetal status on admission

\begin{tabular}{|c|c|c|c|c|c|c|c|c|c|}
\hline \multirow[b]{2}{*}{ Case } & \multirow[b]{2}{*}{ Parity } & \multirow[b]{2}{*}{ Complication } & \multicolumn{3}{|c|}{ Neonate } & \multicolumn{4}{|c|}{ Time interval* (min) } \\
\hline & & & GW & Weight (g) & Apgar & $\mathrm{pH}(\mathrm{BE})$ & A & B & $\mathrm{C}$ \\
\hline 1 & 2 & - & 30 & 1310 & 1 & $6.817(-20.2)$ & 130 & 27 & 157 \\
\hline 2 & 2 & - & 30 & 1743 & 1 & $6.817(-19.0)$ & 224 & 46 & 270 \\
\hline 3 & 1 & GH & 33 & 2384 & 2 & $6.691(-22.0)$ & 272 & 48 & 320 \\
\hline 4 & 1 & - & 35 & 2360 & 1 & $6.641(-20.6)$ & 435 & 26 & 461 \\
\hline 5 & 1 & - & 35 & 2270 & 0 & $6.760(-28.0)$ & 300 & 61 & 361 \\
\hline 6 & 0 & - & 35 & 2469 & 0 & $6.598(-34.4)$ & 110 & 22 & 132 \\
\hline 7 & 2 & - & 35 & 2096 & 4 & $6.920(-19.6)$ & 315 & 26 & 341 \\
\hline 8 & 1 & - & 35 & 2034 & 2 & $6.740(-27.8)$ & 145 & 39 & 184 \\
\hline 9 & 1 & - & 36 & 2522 & 2 & $6.566(-31.7)$ & 60 & 96 & 156 \\
\hline 10 & 1 & - & 37 & 3064 & 5 & NA (NA) & 170 & 128 & 298 \\
\hline 11 & 2 & - & 37 & 2362 & 2 & NA (NA) & 101 & 44 & 145 \\
\hline 12 & 2 & - & 37 & 2480 & 2 & NA (NA) & 160 & 11 & 171 \\
\hline 13 & 2 & - & 37 & 2476 & 6 & $6.594(-27.2)$ & 110 & 58 & 168 \\
\hline 14 & 1 & - & 37 & 2432 & 1 & 6.550 (NA) & 100 & 27 & 127 \\
\hline 15 & 1 & IPU & 38 & 2680 & 1 & $6.700(-28.7)$ & 110 & 9 & 119 \\
\hline 16 & 4 & - & 38 & 2352 & NA & 6.543 (NA) & 105 & 56 & 161 \\
\hline 17 & 0 & IPU & 38 & 2418 & 7 & $6.633(-30.5)$ & 150 & 11 & 161 \\
\hline 18 & 0 & IPU & 38 & 2914 & 6 & $7.100(-17.7)$ & 150 & 71 & 221 \\
\hline 19 & 1 & - & 38 & 2725 & 4 & NA (NA) & 35 & 110 & 145 \\
\hline 20 & 1 & IPU & 38 & 2814 & 0 & NA (NA) & 210 & 29 & 239 \\
\hline 21 & 1 & - & 39 & 3170 & 4 & $6.985(-22.5)$ & 35 & 42 & 77 \\
\hline 22 & 0 & IPU & 40 & 3340 & 4 & NA (NA) & 66 & 43 & 109 \\
\hline Mean & 1.2 & & 36.2 & 2473 & 2.6 & $6.728(-25.0)$ & 159 & 47 & 206 \\
\hline SD & 0.9 & & 2.6 & 454 & 2.1 & $0.164(5.4)$ & 99 & 31 & 97 \\
\hline
\end{tabular}

Complications, including gestational hypertension (GH), preeclampsia (PE), and isolated proteinuria (IPU) at the last antenatal visit; GW, gestational week at delivery; Apgar, score at $5 \mathrm{~min}$; $\dagger$, umbilical artery blood pH (base excess, $\mathrm{mmol} / \mathrm{L}) ; * \mathrm{~A}$, until admission to the facility where delivery took place after the onset of symptoms; *B, until delivery after admission; *C, until delivery after the onset of symptoms; NA, not available; 